\title{
Risco, mercado criminal e interações violentas: etnografia de um conjunto habitacional periférico numa cidade média do estado de São Paulo
}

\author{
Luís Antonio Francisco de Souza \\ Doutor em Sociologia pela Universidade de São Paulo \\ Professor da Universidade Estadual Paulista Júlio Mesquita \\ lafraso@usp.br \\ Bóris Ribeiro de Magalhães \\ Doutor em Ciências Sociais pela Universidade Estadual Paulista Júlio Mesquita \\ Pesquisador do Observatório de Segurança \\ Pública da Universidade Estadual Paulista Júlio Mesquita \\ Gabriel de Sousa Romero \\ Bacharelando em Ciências Sociais pela Universidade \\ Estadual Paulista Júlio Mesquita \\ Mariana Franzolin Valera \\ Mestranda em Ciências Sociais pela Universidade \\ Estadual Paulista Júlio Mesquita
}

Resumo O presente artigo procura explorar os dilemas vivenciados por moradores de um conjunto habitacional periférico numa cidade do interior do estado de São Paulo. A discussão parte da perspectiva da expansão do mercado criminal em conexão com a ampliação dos riscos decorrentes disso, sobretudo, para os jovens moradores do conjunto habitacional. Por meio de uma etnografia, o estudo aborda as interações violentas entre jovens vinculados ao mercado ilegal das drogas e a polícia. A preocupação do artigo é identificar os conflitos, a violência letal e as estratégias de sobrevivência dos moradores do conjunto a partir de sua inserção no mercado informal e ilegal, e averiguar os padrões de resolução de conflitos no interior do chamado tribunal do crime.

Palavras-chave: Risco, mercado criminal, violência, tribunal do crime, polícia.

\section{Introdução}

Os utopianos choram amargamente sobre os louros de uma vitória sangrenta; envergonham-se mesmo, considerando absurdo comprar as mais brilhantes vantagens ao preço do sangue humano. Para eles, o mais belo título de glória é o de ter vencido o inimigo à força de habilidade e artifício. É então quando celebram os triunfos públicos e erguem os troféus, como após uma ação heroica. 
$\mathrm{O}$ presente artigo apresenta resultados preliminares de uma etnografia realizada num conjunto habitacional da periferia de uma cidade média do interior do estado de São Paulo. A etnografia visa mostrar as novas dinâmicas do mercado criminal que estão emergindo no contexto brasileiro contemporâneo. Estas dinâmicas se inserem no mesmo contexto em que antigos e novos empreendimentos imobiliários populares reconfiguram a paisagem urbana e as demandas tradicionais por justiça, e em que os direitos parecem recuar diante de uma nova realidade social. Uma realidade baseada no convívio tenso entre as instituições da justiça e as novas formas de articulação do crime, sobretudo a partir da presença do Primeiro Comando da Capital (PCC) nas comunidades periféricas. Uma aliança perversa começa a se configurar na gestão de locais onde convivem atores e instituições com interesses diversos. Nesta aliança, o espaço local é sempre explorado com base na valorização das velhas e novas mercadorias políticas que estão à disposição nas comunidades periféricas. Neste contexto, a ação atrabiliária da polícia e a presença perversa do crime são redesenhadas na medida em que, embora o controle territorial ainda seja prevalente no mercado das drogas, vai-se verificando, aos poucos, uma mudança nas fronteiras entre o legal e o ilegal, entre o legítimo e o ilegítimo, entre o poder estatal e a nova institucionalidade. Com essa mudança, vão sendo incluídos e ao mesmo tempo excluídos moradores, demandas e percepções sobre a experiência urbana num contexto de capitalismo flexível. ${ }^{1}$

A compreensão da presença do crime e da violência na sociedade brasileira contemporânea aponta para a incompletude do monopólio estatal sobre o controle da violência legitimada. Já foi constatado que, no Brasil, o Estado não se constitui plenamente como garantidor da ordem social e jurídica, sendo, em muitos casos, o primeiro agente a desrespeitar os princípios básicos do Estado de Direito (Adorno, 2002; Pinheiro, 2001). Esse referencial indica a deslegitimação dos direitos humanos no que diz respeito ao criminoso e ao "combate" da chamada violência urbana. Caldeira (2001), ao formular a tese das respostas privadas às demandas por segurança no Brasil, indica uma disjunção dos princípios formais que regem a política estatal. $\mathrm{O}$ autor denuncia uma efetivação parcial dos direitos sociais e dos princípios concretos das garantias legais e institucionais no campo do exercício dos direitos civis. No Brasil, estes últimos ainda estão longe de ser garantidos para parte substancial dos moradores das periferias, onde a violência ainda é o mediador universal dos conflitos. ${ }^{2}$

Silva (2004), ao contrário, acentua que a violência compartilha o espaço social com os padrões de uma sociabilidade aceita como não problemática. Neste caso, não se trata de uma substituição, mas de uma convivência de preceitos mutuamente correlacionados. Assim, as instituições da ordem convivem com as novas institucionalidades impostas pela violência urbana sem que nenhuma consiga uma posição que desestruture a outra. "Na medida em que o princípio que estrutura as relações sociais é a força, não há espaço para a distinção entre as esferas da política, da economia e da moral" (Santos, 2004, p. 61-62). As comunidades periféricas, neste sentido, indicam o nascimento de um novo padrão de sociabilidade, uma vez que passam a inserir-se como participantes "de uma ordem estatal e, paralelamente, da sociabilidade violenta" (p. 74-78).

Diante desse quadro, a etnografia realizada procura descrever o cotidiano do conjunto habitacional monitorado, as forças locais e supralocais que atuam neste cotidiano e as novas modalidades políticas que vêm emergindo ali. $\mathrm{O}$ artigo enfatiza, sobretudo, as interações violentas entre polícia e comunidade, mas também a gestão das ações consideradas ilegais pelo PCC, principalmente no caso dos chamados tribunais do crime.

A disseminação da droga no interior do estado de São Paulo abriu uma alternativa de renda e de poder disponível para os jovens, passando a constituir uma via legítima de acesso aos bens de consumo, à valorização da imagem pessoal e à capacidade de colocar limites à ação policial arbitrária. Vários estudos mostram isto, além de se perceber a ampliação das apreensões de jovens em razão do envolvimento com drogas em todo o estado de São Paulo (Teixeira, 2012). A pesquisa iniciou-se com a preocupação de investigar a situação da letalidade provocada pela ação policial no conjunto habitacional estudado. De partida, percebe-se que o conceito de letalidade, tal como usado nas estatísticas e nos documentos oficiais, precisa ser reconsiderado. O conceito de "mortes em decorrência de intervenção policial" legitima a ação da polícia. ${ }^{3}$ Além disso, a letalidade não inclui outros processos letais em que tomam parte a polícia e as instâncias alternativas de poder, como milícias e grupos de extermínio. Em

1. Evidentemente, esta discussão deve constituir um debate global sobre a formação do estado e a simultânea constituição das fronteiras e sobre a porosidade, indefinição e redefinição crescentes dessas últimas (Das; Poole, 2008).

2. Este debate não se distancia muito das noções de cidadania dos deveres (Zaluar, 1991) e de cidadania regulada (Santos, 1979).

3. Trata-se aqui de realizar uma desconstrução, como fez Lembruber (2002) quando mostrou que o sistema de justiça criminal não pode resolver o problema da criminalidade, nem serve como instrumento eficaz de controle social. O aumento das taxas de encarceramento não reduz as taxas de crimes, e a guerra contra as drogas também não é eficaz para conter o mercado e o consumo. 
termos mais precisos, as violências não são colocadas como pertencendo ao quadro geral de um dispositivo letal no Brasil, como as chacinas, desaparecimentos, corpos achados, execuções sumárias etc.

O quadro da letalidade pode ser ampliado, portanto. O conceito de "vitimização policial" também é problemático, pois coloca claramente o policial como vítima da ação letal. A letalidade, na perspectiva oficial, circunscreve as mortes às situações de perseguições após roubos e sequestros, confrontos e troca de tiros, bem como à "guerra contra as drogas". Ou seja, a letalidade oficial torna-se uma construção jurídica em que prevalece a perspectiva da polícia, que considera como seu direito e dever de ofício matar o oponente que coloca em risco a sociedade. ${ }^{4}$

Para esta definição de letalidade, as mortes de policiais e de não policiais são construídas como sendo parte do mesmo evento, faces da mesma moeda. No entanto, sabe-se, pelos dados de pesquisas, que a morte de um não policial não tem necessariamente correspondência com a morte de um policial (Cano, 1997; Lima, 2011). São fenômenos independentes que requerem uma investigação e compreensão. Se, por um lado, a letalidade é parte da estratégia militar de combate ao crime, por outro, a morte não é um fenômeno aleatório. Os mortos têm identidade étnico-racial, idade e gênero. Os mortos pertencem a determinado espaço geográfico e compõem um grupo que é objeto de uma gestão biopolítica (Foucault, 1985). Assim, a letalidade não parece ser tanto uma questão de ordem jurídica, mas, antes, um problema de gestão de corpos e de trajetórias, e, neste sentido, é parte de um dispositivo letal mais complexo de gestão geral das punições. Mais ainda, as mortes pela polícia, enquanto autorizadas por esse dispositivo, não são puníveis no sentido jurídico, pois não são necessariamente consideradas homicídios: os jovens das periferias são matáveis porque estão em situação de exceção (Agamben, 2004a).

Nesta direção, é importante pensar no sentido do discurso comumente acionado pelas mídias sobre as mortes nos espaços de exceção: "o bandido morreu"; "a polícia interveio e os bandidos morreram"; "houve troca de tiros e os bandidos morreram"; "quem reagiu morreu" ou "quem não reagiu está vivo". $\mathrm{Na}$ perspectiva teórica, o termo bandido já faz referência ao "bando", ao expulso da órbita jurídica, à fronteira entre legal e ilegal, à indiferenciação entre direito e norma, ao "estado de exceção" (Agamben, 2004a). Tem-se aqui um discurso justificador segundo o qual o "bandido" mereceu morrer porque ameaçava a ordem social. E mais: a expressão revela a ideia mais profunda de que "ser bandido já é um passo para a morte", o bandido já está morto, portanto sua morte não é crime. A ação letal da polícia está justificada no interior mesmo da ordem legal, sendo, portanto, constitutiva dela, da mesma maneira que a morte dos cidadãos torna-se objeto de constituição soberana do Estado (Foucault, 1999).

Trata-se, assim, de uma configuração moderna do homo sacer, aquele que pode ser assassinado, mas não é digno de ser sacrificado em um rito religioso. Sua vida, portanto, não encontra proteção político-jurídica nem religiosa (Agamben, 2004a). Sua morte não é passível de punição. Esta consciência da impunidade gera a indiferença de quem mata, como se depreende do discurso de um policial militar entrevistado neste estudo: "eu não mato, apenas aperto o gatilho". O jovem matável pela polícia, e pelo tráfico, pertence, portanto, a essa antiga categoria jurídica, que vem sendo atualizada constantemente nas práticas e discursos da segurança pública. E, nesse contexto, ele se confunde com todas as figuras históricas dos matáveis, num genocídio cotidiano, necessário para a segurança dos "cidadãos de bem”. O matável de hoje cumpre no imaginário da população e da polícia o papel do bandido de outrora (Agamben, 2004b; Hobsbawm, 2010).

Apesar do exposto, a pesquisa observou que os matáveis podem também não ser mortos ou, mais especificamente, suas mortes podem ser cambiadas, manipuladas, negociadas e ocultadas. O artigo, portanto, debruça-se sobre esta aparente contradição do modelo punitivo contemporâneo em seus desdobramentos numa cidade média do interior de São Paulo (Garland, 2008).

\section{Risco e mercado criminal}

Como se verifica pelo quadro acima, as mortes merecem ser deslocadas do eixo interpretativo tradicional, que as coloca como necessárias, por fazerem operar um mecanismo punitivo considerado legal. Mais que isto, elas estão inscritas na dinâmica de um mercado criminal corrente nas periferias, embora não exclusivamente. Evidentemente, são diversas as lógicas que informam a seletividade da morte das vítimas "não inocentes". Não são todos os matáveis que são efetivamente mortos. As polícias prendem um número grande de matáveis que escapam à execução, e a justiça os pune massivamente; afinal, as prisões estão lotadas e, em geral, ocupadas por

4. A violência policial passou a ser utilizada como "instrumento de controle social, e mais especificamente como instrumento de controle da criminalidade". E, neste sentido, é necessário compreendê-la em seu componente ilegal (uso ilegal da força) e em seu caráter ilegítimo (uso desnecessário e excessivo da força) (Mesquita Neto, 1999, p. 130; 133). 
pessoas a quem se atribui o mesmo perfil dos matáveis (Teixeira, 2009, 2012).

A "matabilidade" reforça o universo do risco de ser morto como uma inevitabilidade. Entre os jovens das periferias, comumente se ouvem falas como "a vida é assim mesmo"; "quem tá na chuva deve se molhar"; "ninguém vive para sempre". No interior de uma biopolítica geral da punição, a morte encontra seu lugar. E é a seletividade característica da morte como mercadoria biopolítica que permite fazer o recorte dos "delinquentes matáveis" no interior da criminalidade geral (Foucault, 1985; Misse, 2008, 2011).

Diante desse quadro, seria talvez necessário, como forma de gestão de riscos, pensar uma economia biopolítica da morte - entendendo-se riscos como uma categoria biopolítica, e não meramente econômica. Os riscos são distribuídos na sociedade de forma desigual e disseminam no corpo social uma disputa de individualidades, desarmando os mecanismos tradicionais da solidariedade de condição (Beck, 2010). O crime pode não compensar, mas os riscos não apenas remuneram como também distribuem poder. Isso vale tanto para os grandes mercados financeiros, como para o pequeno traficante de drogas das comunidades periféricas e das comunidades fortificadas, o qual se tornou agora um pequeno empresário num mercado lucrativo. Não se trata mais apenas de inserir os jovens no mercado formal de trabalho por meio das tradicionais estratégias de escolarização. As políticas públicas não mais incorporam os jovens integralmente. A condição juvenil pressupõe agora a participação dos jovens em diferentes dinâmicas difusas na sociedade, nas quais, certamente, o mercado informal e ilegal tem uma nova centralidade (Telles, 2011; Silva, 2008; Leite, 2008). No atual estágio da sociedade, o antigo jovem perigoso, como categoria criminológica e jurídica, passa a ser designado como um jovem em risco, como categoria econômica e biopolítica.

Como se observa, há uma mudança perversa do quadro dos movimentos sociais urbanos no Brasil pós-redemocratização e do mercado de drogas, sobretudo cocaína e crack. As principais cidades brasileiras, cada vez mais, articulam-se em redes ao mesmo tempo concentradas e disseminadas, ressaltando o seu aspecto de um mercado criminal que deve ser controlado, gerido e protegido. A droga vem se transformando numa mercadoria política que mobiliza um amplo mercado, agora não apenas confrontado com a repressão policial criminal, mas também monitorado por outras formas de gestão mais próximas do mercado informal. A rede econômica informal deixa de ser secundária para se tornar, cada vez mais, uma verdadeira economia nas periferias, levando consigo o mercado ilegal a novos patamares de consumo e de venda. Sendo assim, as fronteiras entre os mercados legal, informal e ilegal se romperam completamente, pois estes mercados fazem parte da mesma economia lucrativa e competitiva (Telles, 2011). ${ }^{5}$

\section{A etnografia do conjunto habitacional periférico estudado}

Esta descrição etnográfica procura discorrer sobre as práticas cotidianas dos moradores do bairro periférico selecionado para análise, localizado numa cidade do interior do estado de São Paulo. A etapa inicial da pesquisa, que pretende expandir em outros estudos os limites das fronteiras de análise, construiu o campo sob diferentes abordagens, sendo a etnografia a mais importante. Nesse percurso, utilizaram-se não apenas a observação direta como também conversas informais. A reconstrução etnográfica se deu por meio de anotações em caderno de campo de momentos da vida cotidiana marcados por acontecimentos sobre os quais os moradores emitiram juízos. A etnografia foi mediada por informantes residentes na localidade. ${ }^{6}$ No curso da construção do campo, foram obtidas informações de agentes públicos e de membros de associações que atuam no local. Além disso, evidentemente, usou-se material coletado pela imprensa local e extraído de relatórios realizados por agências supralocais. Este trabalho de pesquisa pode ser tomado como uma "etnografia política", pois a intenção é identificar as redes de poder que estão se constituindo por meio da lógica da disputa pelo território. Sendo assim, esta etnografia tende a percorrer os caminhos de uma "biopolítica dos espaços subalternos", em busca não apenas da rede de ilegalismos, como também das formas legitimadas de distribuição (e concentração) de poder e de mercadorias políticas e econômicas (Misse, 2006; Teixeira, 2012).

A pesquisa remete, portanto, a Elias e Scotson (2000), para quem as relações de poder são exercidas,

5. Beckett e Herbert (2008) sugerem pensar este novo quadro de gestão como uma espécie de governamentalidade espacial, que alia mecanismos novos e flexíveis de segregação e controle de riscos com as formas tradicionais da vigilância policial.

6. Nesse sentido, o estudo se inspira nas reflexões de Whyte (2005) quando este diz que a pesquisa etnográfica pretende incluir os seres humanos, suas vozes e vivências, no quadro geral de reflexão sobre a vida urbana. 
horizontal e verticalmente, por meio de mecanismos de controle político presentes na própria comunidade, sem necessariamente envolver as ações do Estado e das autoridades estatais, mas, ao mesmo tempo, sem deixar de considerá-las em suas diferentes interfaces. As ações políticas que se exercem na comunidade implicam também múltiplas institucionalidades, configurando-se aí não somente uma sociedade contra o Estado, mas também um Estado contra a sociedade, neste caso, contra sujeitos subalternos. O Estado, entretanto, é apenas mais um ator entre outros, mesmo que seja visto como o mais poderoso pelos moradores. De qualquer forma, os grupos são capazes de dar sentido político às relações de força, e estas ganham poder moral. Isto será constatado no mecanismo do tribunal do crime, instituição informal criada pelo PCC para julgar e executar responsáveis por crimes de estupro, dívida de drogas e homicídios, considerados inaceitáveis pela organização (Clastres, 2003).

Alvito (1999), realizando uma etnografia de Acari-RJ, emprega o conceito de localidade para compreender as várias dinâmicas e camadas dessa comunidade, destacando que em um espaço social se entrelaçam instituições locais e supralocais. Ou seja, "uma comunidade não é necessariamente uma tribo, pois no local ocorrem processos de diversos tipos, onde cruzam atores de diferentes níveis". Assim, o autor percebeu que a favela de Acari não existe; o que há ali são "três favelas diferentes, cada uma com um nome, território definido e associação de moradores própria" (Alvito, 1999, p. 183-184). A definição do território da presente pesquisa, como no caso de Acari, depende dos atores e das representações dos moradores. Portanto ela é fluida e está em processo de ressignificação permanente. Certamente ela não corresponde às definições de território adotadas pelos gestores do poder público.

Aqui a noção de periferia mostra seu sentido negativo, estabelecendo assim uma categorização perversa da vida social dos habitantes desses espaços. A periferia chega até a adquirir uma dimensão normativa quando se leva em conta a maneira como os diferentes atores públicos interagem com a localidade. As classificações que a envolvem não são desprovidas de sentido. Na lógica dos atores supralocais, a periferia é vista como um agregado desordenado de favelas ou moradias precárias, como comunidade carente ou como área de interesse especial etc. Para os moradores, a periferia ganha uma denominação concreta, que reflete sua maneira de incorporar os fragmentos de uma realidade extremamente dinâmica. Os espaços públicos da comunidade não necessariamente correspondem aos espaços artificiais criados por arquitetos e gestores das cidades. Por esta razão, quando possível, as categorias nativas são priorizadas e evitam-se os conceitos generalizantes, perspectivas de sentido subalterno. Sobretudo, são evitados aqui os termos administrativos e midiáticos, como complexo ou bairro pobre. O território tem sua espacialidade, e suas fronteiras são bem demarcadas. Embora isto não seja claro para o outsider, a periferia é um espaço socialmente construído, com espacializações fixas e mutáveis. $^{7}$

A periferia pesquisada tem características muito diversas das tradicionais periferias. Trata-se de um local marcado pela existência de um grande condomínio vertical, composto de diversos blocos alinhados e separados pelo espaço de estacionamentos. O conjunto surgiu da remoção de favelas e, aos poucos, foi sendo transformado pelo constante loteamento das áreas contíguas. Localiza-se numa cidade média, com cerca de 230 mil habitantes. O que caracteriza o local como periferia é a distância em relação ao centro e o fato de boa parte do quadrante em que se situa ser composto por classe média baixa ou pobre. A despeito da multiplicação de condomínios horizontais de classe média e média alta na cidade, o quadrante não conta com estas iniciativas. Não existem enclaves fortificados, não existe uma proximidade murada, como ocorre em outras cidades, e, mais particularmente, na capital de São Paulo (Caldeira, 2001).

As moradias dessa periferia, embora de alvenaria, não apresentam acabamento ou, quando ele existe, está em estado de degradação. Elas sofreram várias modificações e, sobretudo, acréscimos para comportar mais um quarto ou fazer a cobertura da garagem. Muitas moradias apresentam portões mais altos e fechados, mas, em regra, a precariedade domina o cenário, mais ou menos monótono e cinza. Nas proximidades do conjunto habitacional, a qualidade das casas e do equipamento urbano vai piorando, e é possível observar a falta de conservação adequada em todos os lugares. Mesmo o parque municipal mais parece um descampado semirrural, onde é possível ver pastagens. As calçadas e o asfalto estão severamente degradados; há mato crescido e lixo espalhado. Os limites entre os bairros desta periferia não são fáceis de se delinear. Os bairros, em geral, terminam nos contrafortes dos paredões que separam a cidade dos vales circundantes, numa repetição monótona dos limites entre periferia e campo.

7. Evidentemente, a periferia também é recortada pelos espaços impostos por instituições supralocais, como a polícia, e locais, como o tráfico. Assim os territórios ganham materialidade dentro da estratégia geral da força transmutada em guerra, em que as armas e as mortes representam os limites lógicos desses territórios, em sua condição de espaços de exceção (Birman, 2008; Leite, 2008). 
O conjunto habitacional observado, que ocupa o extremo sul da periferia, foi entregue aos moradores em 1996, sem acabamento interno, pela Companhia de Desenvolvimento Habitacional e Urbano (CDHU). A ocupação da parte sul dessa periferia data dos anos 1970. O conjunto conta com aproximadamente 880 apartamentos divididos em 40 blocos e com uma população estimada de mais de três mil pessoas. ${ }^{8}$

Ao longo dos anos, o entorno do conjunto recebeu intervenções municipais, como posto de saúde, escola e uma creche. O conjunto habitacional é chamado de "favela colorida", "predinhos" ou CDHU. Desde o início, vem experimentando uma debandada de proprietários. As razões alegadas para isto são muitas: distância do centro comercial da cidade, espaço estigmatizado, transporte precário, falta de opções de lazer, educação e saúde, falta de espaço das unidades habitacionais ou simplesmente a presença do tráfico. ${ }^{9}$ Enfim, a rotatividade de moradores é relativamente alta.

Muitas unidades estão irregulares, pois foram ocupadas ou vendidas pelos traficantes locais por quatro ou cinco mil reais, ou são alugadas por moradores em busca de um complemento de renda. Os moradores, em geral, têm empregos precários, desqualificados ou informais. Encontram-se, em boa parte, ocupados em bicos de todos os tipos, seja entrega de gás, pequenos consertos ou comercialização de produtos considerados essenciais. Há também muitos desempregados, o que pode ser visto em função da permanência de adultos durante os dias de semana. Também os traficantes utilizam os imóveis como refúgio ou como local de preparo e guarda das drogas. Se a ocupação das unidades é irregular, os moradores percorrem igualmente um longo processo de regularização. Aos poucos, eles foram criando puxados ou adaptando locais para reunião num terreno vazio em frente ao condomínio. De qualquer forma, trata-se de uma comunidade murada e, sobretudo, vigiada. Os olheiros do tráfico estão posicionados em locais estratégicos e, mesmo no horário da manhã, perto do meio-dia, já é possível observar o movimento de preparação para um dia de trabalho nas bocas.
A degradação e a baixa qualidade dos equipamentos públicos saltam à vista. Lixo jogado no chão, lixeiras transbordando, muros quebrados e blocos sem pintura, com muitos puxadinhos, "gatos" e todo tido de adaptação de espaços vazios que vão se convertendo na moradia de alguém. $O$ conjunto habitacional parece uma máquina perversa de desumanização. Os visitantes do local são rapidamente identificados, da mesma forma que os carros que aparecem no local ou em sua proximidade. Uma única linha de transporte público liga o bairro ao centro da cidade. Uma parada de ônibus fica localizada junto ao portão principal do conjunto vertical.

O conjunto transformou-se em uma minicidade de Deus, com todos os problemas e dilemas enfrentados pela famosa Cidade de Deus de Zaluar (1994). Depois de anos de lutas sociais por melhorias e de muito tempo de degradação ambiental do conjunto (considerando que os moradores continuam trabalhando em atividades subalternas e informais), percebem-se poucas melhorias substantivas na condição de moradia. ${ }^{10}$

No âmbito do programa Minha Casa, Minha Vida, na modalidade Faixa 1 (empreendimentos habitacionais destinados às famílias com renda mensal bruta de até $\mathrm{R} \$ 1.800,00)$, está em fase de conclusão um novo conjunto habitacional vertical, limítrofe ao aqui apresentado. O novo conjunto compreende 816 apartamentos divididos em 51 blocos. Nas proximidades, também está sendo aberta à exploração imobiliária uma área de loteamento popular. O conjunto prestes a se concluir vem trazer um agravamento a uma periferia que já tem problemas estruturais de toda ordem, incluindo falta de transporte, de escolas, de saúde e de segurança. Com esse novo empreendimento, a periferia contará com um complexo de conjuntos num local caracteristicamente isolado do tecido urbano da cidade e constituído como um verdadeiro espaço de exceção legalizado e legitimado pelas estruturas supralocais atuantes no bairro.

A construção desse novo conjunto foi processada, é claro, sem a devida consulta aos moradores da região. O projeto vai ampliar as carências históricas do bairro, que, afinal de contas, terá de assimilar

8. Por meio de fotos antigas, percebe-se que a construção do empreendimento e do entorno ressalta o aspecto inicial de acampamento no meio de lugar nenhum. Nos dias de hoje, o conjunto habitacional é circundado por um entorno social e economicamente vibrante, mas ainda tem o isolamento como índice. Comparando-se essas fotos com o atual conjunto, pode-se, certamente, falar que as políticas habitacionais populares no Brasil são caracterizadas pela implantação de uma sociabilidade perversa, parafraseando Michel Foucault (1985).

9. Lembra Alvito (1999) que o número de pessoas efetivamente envolvidas com o mercado das drogas é relativamente pequeno, mas o impacto das drogas na favela é imenso, não apenas em função de fatores econômicos, mas também de fatores sociais, culturais e políticos.

10. O Brasil reproduz uma política urbana cuja característica básica é inserir excluindo. Condomínios populares de baixa qualidade são construídos em periferias, sem nenhuma dinâmica de integração à cidade. O acesso dos moradores aos direitos sociais e aos direitos civis é problemático. A implantação de moradias populares de larga escala sempre coloca os pobres nos arranjos informais e violentos, o que justifica a guerra urbana e a privatização de serviços básicos (Zaluar, 1994). 
uma quantidade significativa de novos moradores. Consequentemente, haverá um aumento expressivo de clientela para o mercado informal e ilegal, num jogo em que o populismo político e os interesses de empreendedores imobiliários nunca perdem. O novo conjunto atenderá a uma política de desfavelamento que vai tirar moradores de outras regiões e bairros da cidade e colocá-los em um contexto vicinal artificial e problemático. Apenas como exemplo, esta etnografia já deu conta de que o novo território foi loteado pelos traficantes locais, como forma de ampliar o potencial do mercado ilegal. ${ }^{11}$

O comércio da periferia é muito variado, contemplando todos os itens de necessidade. Mas, no entorno do conjunto, as opções comerciais são poucas, restringindo-se a algumas igrejas evangélicas, um clube de uma associação industrial e uma grande praça devastada. A avenida principal do bairro apresenta um bom fluxo de veículos, com a linha de ônibus e a circulação de vans de transporte escolar. O comércio da avenida restringe-se a alimentos e uma barraca que vende bebidas, cigarros, lanches, doces, balas e folhas de seda. Na rua da entrada secundária, há alguns puxadinhos ocupados por mercearias e botecos. A creche fica espremida no meio deste comércio informal. É neste espaço que se concentram as "biqueiras" (ou bocas), mas elas existem também no interior do conjunto, situando-se próximo às janelas dos quartos dos apartamentos térreos ou nas laterais dos blocos.

\section{Os moradores e os jovens da localidade}

A localidade estudada (periferia sul) compartilha com a periferia norte da cidade os mesmos problemas, inclusive, a presença da violência. A cidade conta com uma média anual de 25 mortes violentas. ${ }^{12}$ Uma de suas características é a distância significativa das periferias em relação ao centro. Estas configu- ram áreas segregadas e pouco interconectadas, com pouquíssimas vias de acesso ao centro e um escasso transporte público de massa.

Não é preciso dizer que nessas periferias há uma concentração da pobreza e de jovens não brancos e que a presença da polícia é conspícua: comandos, patrulhamento e fiscalização setorizada na área são comuns, com constantes batidas por motos e motoqueiros, em busca de contrabandos, carros roubados, drogas, foragidos da justiça e armas. ${ }^{13}$ A presença da polícia militar é constante no bairro, numa ciranda de patrulhamento rotineiro com a presença noturna da força tática. A polícia civil também faz batidas nos apartamentos em busca de usuários e de traficantes, na maior parte das vezes, sem a necessária autorização judicial.

Moradores relatam o desconforto com estas ações, consideradas discriminatórias, pois incidem sobre trabalhadores e criminosos indistintamente. Segundo o discurso oficial, tais ações visam coibir o comércio de drogas. ${ }^{14}$ Para a polícia, o conjunto habitacional é uma área de interesse especial e deve ser observado atentamente. Para os moradores, a polícia não é bem-vinda, uma vez que ela não resolve o problema do tráfico. Em geral, eles silenciam o assunto, pois não querem se envolver com esses casos. Quando uma ação policial é bem-sucedida nas apreensões de drogas, a economia local sofre as consequências, e os moradores expressam isso nas conversas e na aflição pela falta de dinheiro para as despesas diárias. Mas o conflito entre polícia, moradores e traficantes é cotidiano.

Embora as interações entre polícia e moradores jovens sejam marcadas pela truculência, poucas mortes são relatadas no território. Estes assuntos são considerados tabus na comunidade. As mortes pela polícia são registradas nas notícias de imprensa, segundo as quais elas ocorrem, em sua maioria, em confrontos com grupos armados, no momento em que efetuam roubos ao comércio ou aos bancos da cidade. Ou seja, esse tipo de morte acontece fora do espaço do bairro, no centro da cidade ou em áreas limítrofes dos bairros com concentração de ativida-

11. Essa questão do impacto do novo empreendimento na região não deve ser subestimada. A lógica do acúmulo social de violência pode se impor nas relações vicinais, assim como, certamente, haverá um impacto econômico visível na economia formal, informal e ilegal (Misse, 2008). Seria também importante acrescentar que o processo de ocupação do novo condomínio será mesmo traumático, de certa forma, porque implicará talvez um conflito de perfil social, econômico e cultural entre os moradores do local. Mais ainda, consequências da consciência de pertencimento ao local poderão ser observadas, e, neste sentido, seria conveniente um acompanhamento etnográfico do processo no mesmo modelo do estudo realizado por Elias e Scotson (2000) - embora, no caso presente, o conjunto tenha uma fragilidade muito grande se levarmos em conta que a maioria das lideranças legítimas estão, de alguma forma, ligadas ao mercado criminal.

12. Cf. <www.observatoriodeseguranca.org>. Acesso em: 2 mar. 2016.

13. As opiniões dos moradores a respeito da polícia e, sobretudo, do tráfico de drogas são oblíquas e sussurradas ao pé do ouvido. A regra do silêncio é absolutamente imperativa (cf. também Velho; Alvito, 1996).

14. Feffermann (2006) aponta a relação violenta entre os jovens do tráfico e a polícia. Também discute a crueldade do tráfico, citando a exposição de corpos, os corpos jogados em valas, os rituais de humilhação e a degradação dos inimigos. O comércio de drogas como business reduziu a violência no território, ainda que mantenha as clientelas fiéis e a comunidade aterrorizada. 
des comerciais. Muitas dessas ações desdobram-se em perseguições seguidas de acidentes, troca de tiros e mortes.

Um fato que ainda está na memória coletiva da periferia é a morte de Wander Eduardo Ferreira, conhecido como General. Ele era considerado um dos líderes do PCC e residia na periferia. Cumpria pena de 61 anos de prisão por dois homicídios e vários roubos a bancos. Foi resgatado da prisão por um grupo armado. Após sua fuga, a polícia deflagrou contra ele uma perseguição que empregou 60 policiais. Segundo uma notícia veiculada na imprensa, os criminosos do grupo de resgate teriam resistido à ação da polícia. Toda a ação resultou na morte de quatro pessoas, incluindo três criminosos e um policial militar. Um soldado foi ferido, e cinco envolvidos no resgate foram presos. O General, atingido por oito disparos de arma de fogo, foi encaminhado ao hospital ainda vivo, mas não resistiu aos ferimentos. Este fato chamou a atenção até mesmo da imprensa nacional. ${ }^{15}$

Em razão da chamada pacificação das comunidades periféricas, em que o PCC teve importante papel, os crimes violentos deixaram de ocorrer no local em questão, dentro do domínio territorial e moral do tráfico. E quando ocorrem, são submetidos à lógica da rejeição moral, culpabilização e execução dos seus perpetradores, por meio dos chamados tribunais do crime. ${ }^{16}$ A atividade ilegal passa a implicar, para os jovens, um grau de risco compatível com sua posição relativa na estrutura do mercado, isto é, correspondente ao seu status político no interior da organização. Em contrapartida, resulta também em maior rendimento econômico e reconhecimento social local. No final das contas, o risco acaba sendo recompensado de várias formas.

Entre os riscos da atividade ilegal, está a rearticulação do mundo do trabalho, em que a liquidação do emprego e das garantias empregatícias coloca milhares de pessoas às margens do mercado formal de trabalho, obrigando-as literalmente a se virar para sobreviver com algum grau de dignidade. E mais: na sociedade do risco, uma vida dedicada a uma profissão segura e com garantia de aposentadoria perde valor entre os jovens. No mercado das drogas, a busca do ganho e de melhores condições de vida decorre do risco assumido. O investimento éliquidável rapidamente, mas a morte e o encarceramento são presenças constantes e, em algumas circunstâncias, até valorizadas. Dowdney (2002, p. 103) relata que muitos jovens do tráfico disseram "sentir prazer ao usar um revólver e gostar da adrenalina produzida por uma forma de viver tão estimulante".

Os jovens que trabalham no crime tendem a superestimar sua posição nesse mercado e a ostentar sua condição abertamente. A busca por uma posição afeta não somente os que se vinculam às biqueiras, mas também aqueles que se dedicam a vender lança-perfume de fabricação caseira ou outras drogas sintéticas. O mercado é dinâmico e regulamentado por uma disciplina rígida: vez ou outra, os joven ${ }^{17}$ têm que repor a droga usada para consumo pessoal.

As batidas policiais, as disputas territoriais, os tiros, a morte, a presença dos usuários de drogas e o cheiro da maconha (e outros tantos cheiros) marcam a vida cotidiana no território investigado. Os conflitos são resolvidos localmente, com a interferência do "patrão". O 190 não deve ser acionado. Há, no entanto, entre os traficantes e as lideranças locais uma linha de comunicação aberta para a resolução de problemas comuns. O traficante promove festas, distribui itens de necessidade e dá presentes. ${ }^{18}$ As biqueiras, segundo os administradores, chegam a movimentar, no total, cerca de vinte mil reais por semana. Existem no conjunto seis biqueiras, sendo que duas estavam desativadas à época da pesquisa porque seus proprietários tinham sido presos e não conseguiram alugá-las. Os pontos são organizados. Os "lagartos" anunciam a mercadoria: "tá tendo, tá tendo!" O dono da boca tem um rígido controle dos horários e do pessoal. As biqueiras só ficam vazias quando não tem a mercadoria. Nas biqueiras do bairro, há jovens e adultos, homens e mulheres trabalhando. $\mathrm{O}$ administrador circula por ali com muita cautela. Às vezes, ele atende os conhecidos ou vende quantidades maiores. Uma boa parte dos jovens das biqueiras diz ter passagem pela Fundação Casa (Centro de Atendimento Socioeducativo ao Adolescente). Percebe-se, claramente, que a passagem por instituições carcerárias assim como o porte de armas são vistos como indicadores de status e de crescimento na hierarquia do crime.

15. Cf. matéria da Folha de S. Paulo, de 2/11/2000.

16. A relação entre a cadeia e a comunidade tem se tornado mais problemática desde que o PCC se impôs no interior dos presídios, assumindo um papel de ator privilegiado na organização das estruturas sociais da comunidade (Dias, 2013).

17. A questão da juventude não deve ser colocada numa perspectiva normativa da quebra de valores sociais, mas numa perspectiva prospectiva em que novos valores estão sendo criados. Desse ângulo, para entender a vivência cotidiana do risco, é necessário considerar tanto a condição juvenil de vulnerabilidade, quanto a condição existencial do enfrentamento do risco como tragédia humana (Feffermann, 2006).

18. "A imagem do traficante sempre foi ambivalente e amedrontadora" (Zaluar, 1999, p. 218). As pesquisas denotam que, nessa percepção, as categorias respeito e desrespeito tornam-se predominantes nas falas dos moradores. Estes assinalam que os traficantes devem demonstrar mais respeito para com a comunidade, evitando atos como exibições de armas, venda escancarada de drogas ou mesmo imposição do medo às pessoas que residem no local (Silva, 2008; Cardoso, 2015). 
No que se refere à atuação de mulheres no mercado ilegal, suas relações com o crime, segundo elas, justificam-se pelo fato de seus homens terem sido presos. A venda de drogas é uma forma de manter a família e o "jumbo" - produtos levados ao companheiro na prisão como forma de suprir a deficiência do Estado no provimento de recursos aos detentos. Além de venderem a droga, as mulheres cuidam das crianças e da casa. Muitas, quando não têm serviço fixo, fazem bicos para atender às necessidades de suas famílias. Vê-se, entre elas, um entrelaçamento inquietante do informal com o ilegal. A questão de gênero é, portanto, um aspecto relevante na reconstrução etnográfica, marcada por uma reconfiguração do papel das mulheres no crime. Em geral, nos locais inscritos no cenário estudado, elas assumem todas as responsabilidades ligadas à família e às crianças. Em grande parte, estão à frente na luta por melhorias locais e nas filas dos serviços sociais. E mais: atualmente elas estão tomando a frente também nas atividades do mercado informal e, evidentemente, no mercado ilegal. Muitas vêm herdando as bocas de seus companheiros presos e tomando posição de destaque nas relações com o universo essencialmente masculino do crime e da cadeia. Mas, a despeito desses papéis, continuam vinculadas à lógica da reprodução da desigualdade de gêneros, pois ainda são elas que se esmeram nas visitas às prisões e na feitura do famoso "bonde" - quando vão visitar os maridos e parentes em penitenciárias do interior paulista. Numa rápida observação aos pontos de ônibus, nas manhãs de domingo, é possível flagrar filas enormes de mulheres e crianças em suas visitas à Penitenciária, ao Centro de Referência e à Fundação Casa, situados nas proximidades da cidade.

As cenas corriqueiras da movimentação do mercado são acompanhadas pelo olhar fugidio dos moradores do condomínio. A proximidade do tráfico sempre gera discussão entre os moradores. Um deles, que é vigia noturno e mototaxista, trabalha transportando as mulheres em visita às prisões, e diz que as drogas degradam o local. Outra moradora que já foi usuária de crack, e que também tem no transporte local sua fonte de renda, não condena o tráfico, embora critique os excessos. O dono de um puxadinho comercial reclama que a biqueira provoca a queda das vendas. Mas o que impera é a "cumplicidade constrangedora" entre o morador e o crime. ${ }^{19}$ Os moradores às vezes incorporam os discursos sobre segurança e violência, sussurrando a necessidade de medidas mais efetivas. O sutil processo de diferenciação social no conjunto pode responder por este desconforto, sofrido essencialmente pelos moradores que dependem do mercado local ou têm empregos seguros. Esses moradores projetam para si e para seus filhos uma mobilidade social vertical, porém sem sair do local. Mas, em geral, as pessoas e famílias que progridem deixam o conjunto em busca de bairros melhores. Muitos moradores experimentam uma "(i)mobilidade social horizontal", que lhes dá a chance de sonhar com uma vida melhor no conjunto. ${ }^{20}$

\section{A morte no interior da biopolítica do mercado criminal}

As notícias de violência policial utilizadas nesta etnografia foram derivadas da imprensa local dos últimos cinco anos e indexadas através de buscas simples em meio eletrônico, com chaves de investigação do tipo: "confronto policial", "policial morre", "policial mata", "bandido morre", "bandido mata", entre outras. Com a ajuda destas chaves de busca, voltadas para o registro de narrativas de mortes violentas ligadas ao contexto de criminalidade urbana, foram reunidas 73 notícias publicadas por seis diferentes veículos. Em síntese, o material encontrado - incluindo o caso de notícias repetidas por diferentes veículos de imprensa ou ainda casos que se desdobram em mais de uma reportagem - pode ser disposto em quatro grupos: fatalidade ("Motociclista morre atropelado após perseguição policial"); confronto ("Polícia Militar troca tiros com bandido na zona oeste"); cumprimento do dever policial ("Pai e filho morrem em confronto com a polícia na região"); e tragédia ("Tragédia em X: PM mata ex-mulher e companheiros a tiros"). As notícias do tipo "b" são maioria na pesquisa. Estão ligadas, maiormente, a casos de roubo (em maior número a agências bancárias e caixas eletrônicos) e, subsequentemente, a perseguições e confrontos.

As cifras da letalidade não são muito altas (nem confiáveis) para a região pesquisada, e isso fica evidente na busca por notícias e outras fontes de dados. A recomposição da narrativa das ocorrências

19. Esta questão mereceria uma reflexão à parte, pois a ideia de cumplicidade aqui aventada não deve ser assumida em sua acepção jurídica, e oscila entre uma aceitação acrítica e uma recusa velada, mas sempre com um componente de constrangimento evidente.

20. É necessário discutir mais detidamente o problema da mobilidade social no conjunto. Em geral, espera-se que o movimento social ascendente leve as famílias a deixar o local em busca de bairros considerados melhores e mais seguros. No entanto, a etnografia mostra que esta mobilidade é limitada a uma circulação intraperiférica, para bairros vicinais ao conjunto ou para outras periferias. Pode-se até dizer de uma "mobilidade imobilizante" do ponto de vista social e econômico, considerando a precariedade do mercado de trabalho local. 
e o exercício de análise dos fatos nos levam também a outra conclusão: em geral, as notícias tendem a culpar a vítima não policial por sua própria morte. Já no caso de policiais mortos, as narrativas ressaltam o heroísmo da profissão, mesmo quando estas mortes ocorrem em período de folga, o que é bastante comum. A morte do policial "no exercício do dever" vem permeada das honras institucionais. A morte de um não policial, por sua vez, é relatada por um discurso parcial e que ressalta a desproporção entre o número de policiais e o de criminosos e apresenta um cenário em que os criminosos atacam e os policiais se defendem ou defendem a sociedade. Ou seja, a imprensa elabora a notícia de forma que a ação letal seja sempre considerada legítima e justificada.

A imprensa local não relatou nenhum caso envolvendo chacina ou linchamento no conjunto habitacional estudado. Uma notícia interessante refere-se à prisão de um jovem portando arma de fogo. Segundo ele, a arma fazia parte da preparação para uma "guerra entre traficantes" de diferentes bairros. Não obstante a escassez de notícias (e de pesquisas $)^{21}$ sobre a atuação do tribunal do crime no bairro pesquisado, estão se tornando comuns as matérias a este respeito. Em 14 de abril de 2015, a notícia de uma morte sacudiu a população do conjunto habitacional. Conforme a imprensa local, a polícia civil estaria investigando a morte do auxiliar de serviços gerais, TCL, de 21 anos, morador do bairro, na zona sul da cidade. Ele foi alvejado por um "garupa" de motocicleta, quando saía de seu apartamento, e veio a falecer no hospital. Segundo a notícia, a polícia militar foi acionada e fez buscas pela região, detendo um suspeito. $\mathrm{Na}$ opinião das testemunhas que deram entrevista ao jornal, tratava-se de "crime de rixa". Um familiar de TCL afirmou que ele era trabalhador e tinha uma filha: "A pessoa que fez isso deixou uma menina de um ano sem pai".

No conjunto habitacional, o clima era de comoção e de tristeza. Segundo os moradores que presenciaram o fato, o crime ocorreu numa passagem entre blocos de apartamentos. Antes havia ali um muro, mas foi derrubado pelos traficantes para facilitar $\mathrm{o}$ acesso e a fuga dos jovens das biqueiras. As pessoas do bairro diziam que a morte havia sido provocada pelo envolvimento amoroso dos dois jovens com uma mesma jovem de um bairro vizinho. O Sete, um homossexual que fornece cápsulas na área para pó de cocaína e pedra de crack, e o Cabeça, gerente da biqueira mais próxima ao local do crime, foram testemunhas. Este último afirmou estar junto com o TCL no momento do homicídio: "Nós estávamos fumando um cigarro de maconha quando chegaram o Motoqueiro e o Fulaninho. O Fulaninho chamou o TCL de 'talarico' e o agrediu com o capacete da motocicleta". Nesse momento, apesar de a vítima não expressar reação à agressão, Fulaninho puxou a arma e efetuou um disparo certeiro.

Várias pessoas clamavam vingança, pois o motoqueiro e o "garupa" moravam num bairro rival, também responsável pelo abastecimento de drogas da zona sul. Portanto, havia já uma disputa territorial entre os traficantes desses dois bairros. Mas o boato era de que o crime mencionado não tinha relação com as disputas do tráfico, nem com a hegemonia da organização que controla as prisões paulistas.

Trocaram-se comentários depreciativos sobre os locais rivais. Fulaninho e o Motoqueiro desapareceram de vista. As pessoas do condomínio perguntavam-se: "O Partido não vai vingar a morte?" Nas horas seguintes ao crime, circulou a notícia de que um "salve" havia sido expedido da prisão: "morte deve ser paga com morte!". No bairro, as testemunhas foram convocadas para dar o resumo dos fatos no tribunal do crime. Uma ex-detenta, esposa de um membro da organização, não largava o celular, tentando esquivar-se da participação no julgamento. Ela falava com os "irmãos presos" nas unidades do sistema penitenciário e com os "irmãos da quebrada" (aqueles que estavam em liberdade). Os nomes de envolvidos indiretamente também eram citados nas conversas. Ter proximidade com os envolvidos ou ter alguma informação útil sobre os motivos do crime já era suficiente para ser considerado cúmplice pelos "irmãos". A jovem que deu entrevista ao jornal não tinha permissão para fazê-lo, por isso seria chamada a prestar contas na prisão. A movimentação no bairro era intensa, a expressão das pessoas era de revolta ou de medo. O PCC estava sendo acionado para resolver o problema, sobretudo porque, segundo os moradores, um crime de morte não podia ficar impune.

Órfão de pai, TCL tivera uma infância pobre, como boa parte das crianças do conjunto habitacional. A mãe tornou-se viciada em pedra de crack e vivia constantemente metida com os "noias" da cracolândia local. Depois de muitos anos, conseguiu se livrar do vício. O irmão de TCL foi encaminhado para a Fundação Casa ainda bem jovem, por tráfico e furto. Ele também acabou viciado em crack. Não era raro ver mãe e filho compartilhando o cachimbo. Segundo

21. A pesquisa acadêmica sobre o tribunal do crime é ainda incipiente. Entre as abordagens do tema, destacamos o estudo feito por Jacqueline Sinhoretto (2014) sobre os conflitos violentos entre PCC e polícia militar em São Paulo, no ano de 2012. Esse ano foi marcado por uma escalada da violência letal no estado em razão da política de enfrentamento adotada pela Secretaria de Segurança Pública, que usou principalmente a Rota como linha de frente no combate ao PCC e aos tribunais do crime. As consequências, absolutamente violentas, tiveram repercussão internacional. 
moradores, na verdade, o TCL havia sido criado pelos avós e por vizinhos, tornando-se um jovem estimado na comunidade. Era pai de uma menina e mantinha bom relacionamento com a ex-companheira, apesar de viverem separados. Trabalhou em vários lugares $\mathrm{e}$, quando não tinha um emprego fixo, cortava cabelos e "fazia o corre" (algum serviço ilícito). Gostava de música "de responsa" e usava roupas de grife para ostentação. Nas rodas, lá estava ele soltando "pipas", fazendo firulas nas motos e fumando um beck enquanto dava uma espiada no celular. Era bom de bola e, nos fins de semana, defendia o time do local. Mas, apesar de suas qualidades, não fugia das brigas.

A noite do velório de TCL "foi sinistra", como disse um jovem amigo que compartilhava o apartamento com ele. O conjunto habitacional estava vazio, poucas pessoas circulavam nas ruas. $\mathrm{O}$ aspecto da noite era sombrio, como o havia sido a morte de TCL. O velório foi organizado pelos moradores. Ajudaram na compra do caixão e das coroas de flores: "saudades do time", "saudades dos moradores do CDHU". Faixas de igrejas evangélicas disputavam o espaço do cerimonial fúnebre. Foram distribuídos cachorros-quentes e refrigerantes durante a noite do velório e durante o dia do enterro. A sala simples do velório estava repleta de pessoas entristecidas. Os "irmãos" cochichavam em pequenos grupos. O comentário geral era de que duas "caçadas" estavam em andamento, uma organizada pela polícia e a outra, pelos "irmãos". Comentava-se que a polícia estava de butuca na comunidade para encontrar o perpetrador ou para armar uma "casa de caboclo" (armadilha) para os "irmãos". O clima durante o velório foi tenso, já se falava na reunião do tribunal do crime e nas possibilidades de execução do Fulaninho, da jovem acusada de ser o estopim do assassinato e do Motoqueiro. Decisões estavam sendo tomadas a respeito da punição: morte com tortura ou apenas espancamento.

O caso daquele tribunal do crime tornou-se matéria de jornal. Segundo a imprensa, a execução dos culpados não aconteceu porque a polícia militar interveio a tempo: várias viaturas cercaram o local. Houve correria e fuga através de um matagal próximo à casa onde estava acontecendo o julgamento, na zona oeste da cidade. $\mathrm{O}$ assassino escapou. Pelo menos dezenove participantes do julgamento foram detidos pela polícia. Todos foram ouvidos, qualificados e liberados.

Segundo um morador que estava presente ao tribunal, "caguetaram a fita", ou seja, a polícia foi avisada do julgamento por um parente de Fulaninho: "só sei que a menina, a avó e a mãe dela estavam presentes [ao tribunal], o Fulaninho e o Motoqueiro também". ${ }^{22}$ A sentença estava para ser proferida quando a polícia chegou. Foi uma correria. O "mocó" (esconderijo) da reunião dava para um matagal. Fulaninho e Motoqueiro conseguiram escapar. Meses após a realização do tribunal, Fulaninho foi preso por tráfico de drogas. Sendo menor de idade, cumpriu alguns meses de medida de internação e foi solto ao completar dezoito anos. Com o Motoqueiro, nada ocorreu. Nada aconteceu também com a garota causadora do incidente. Os moradores ficaram divididos quanto à sua punição, e muitos esperavam que algo fosse feito contra ela e sua família. ${ }^{23}$

Outro caso de realização de tribunal do crime na cidade em questão tornou-se notícia em março de 2016. Um empresário de 39 anos, proveniente de uma família considerada tradicional na cidade, foi encontrado morto, jogado nas encostas de um dos vários penhascos que contornam o centro urbano da cidade. O tribunal o havia sentenciado pelo estupro de uma jovem. Condenado à morte "por tijoladas", ele conseguiu furtar-se desta sentença por meio da intervenção de uma viatura da polícia militar. Em uma patrulha de rotina, a polícia perseguiu e interceptou um automóvel que lhe parecera suspeito. No interior do veículo, foi encontrado o empresário, afirmando ter sido vítima de tortura, e mais quatro ocupantes. Três deles foram presos e indiciados por sequestro e tortura. O outro, segundo a notícia de imprensa, era um jovem sobre cuja identidade não havia informações. O fato marcante é que o empresário, depois de liberto, foi novamente capturado pelos vigilantes, sendo que, desta vez, não escapou. Sofreu novas torturas e seu corpo foi arremessado do penhasco. Desta feita, cinco pessoas foram presas, quatro homens e uma mulher. Todos eles foram indiciados por homicídio, formação de quadrilha e tráfico. O caso continua em andamento.

Esta breve descrição do dispositivo punitivo acionado pelo PCC mostra o grau de inserção do mercado criminal, com suas regras e lógicas, nas comunidades periféricas marcadas pela presença do crime. Ao mesmo tempo, indica novos aspectos da relação entre risco, crime e sociabilidade violenta. Nas relações sociais e de poder construídas nas periferias, o tribunal do crime vem não apenas contribuindo para o surgimento de novas dinâmicas, como também produzindo sujeitos marcados pela infâmia, em graus ainda pouco explorados pela pesquisa acadêmica (Foucault, 2003).

22. Durante a realização dos tribunais do crime, ocorre a articulação de toda uma rede de contatos, que envolve a presença de membros do PCC como jurados (inclusive os que estão dentro dos presídios, através de celulares), vítimas, réus e testemunhas. Em caso de condenação, o veredito e a execução da pena são imediatos.

23. Desde então, ocorreram outros desdobramentos do caso, mas não influenciam no relato aqui apresentado nem ajudam na compreensão do dispositivo punitivo acionado pelos tribunais do crime. 


\section{Conclusões}

Temos a tendência de conceber as questões da segurança apenas pelo prisma do combate ao crime e do direito penal/punição, sem uma visão mais ampla de gestão e governança públicas. A propósito, estamos diante de uma nova onda de militarização da segurança pública no Brasil? E este processo alimenta a persistência da violência letal, sobretudo nas ações das polícias militares?

Esta descrição etnográfica do contexto da ação policial em uma cidade do interior paulista pretende apenas abrir o debate, colocando ainda as especificidades da condição juvenil e de gênero na conjuntura do mercado ilegal e letal. A etnografia realizada até aqui mostra que, em geral, a gestão dos ilegalismos populares passa também pelo mercado ilegal, no qual a polícia e a letalidade têm parte importante. Sob esta perspectiva, fugindo a uma visão simplificada em que a letalidade é algo que deve ser controlado ou combatido, a pesquisa pretende ampliar o quadro analítico, mostrando que a letalidade funciona e faz funcionar não somente um dispositivo militarizado de segurança, como também mecanismos de punição generalizada.

\section{Referências}

ADORNO, Sérgio. Monopólio estatal da violência na sociedade brasileira contemporânea. In: MICELI, Sérgio (Org.). O que ler na ciência social brasileira (1970-2002). São Paulo: Sumaré, 2002. v. 4, p. 267-307.

AGAMBEN, Giorgio. Estado de exceção. São Paulo: Boitempo, 2004a.

AGAMBEN, Giorgio. Homo sacer: o poder soberano e a vida nua. Belo Horizonte: Humanitas, 2004b.

ALVITO, Marcos. Um bicho de sete cabeças. In: ZALUAR, Alba; ALVITO, Marcos (Org.). Um século de favela. 2. ed. Rio de Janeiro: Editora da FGV, 1999. p. 181-208.

BECK, Ulrich. Sociedade de risco: rumo a uma outra modernidade. São Paulo: Editora 34, 2010.

BECKETT, Katherine; HERBERT, Steve. Dealing with disorder: Social control in the post-industrial city. Theoretical Criminology, v. 12, n. 1, p. 5-30, 2008.

BIRMAN, Patrícia. Favela é comunidade? In: SILVA, Luiz Antonio Machado da. (Org.). Vida sob cerco: violência e rotina nas favelas no Rio de Janeiro. Rio de Janeiro: Nova Fronteira: Ed. Faperj, 2008. p. 99-114.

CALDEIRA, Tereza Pires do Rio. Cidade de muros: crime, segregação e cidadania em São Paulo. São Paulo: Edusp: Editora 34, 2001.

CANO, Ignácio. Letalidade da ação policial no Rio de Janeiro. Rio de Janeiro: Iser, 1997.

CLASTRES, Pierre. A sociedade contra o Estado: pesquisas
A concepção bélica da segurança e das polícias permite a aceitação de excessos dentro do quadro mais amplo de uma guerra continuamente deflagrada. Afinal, em situação de guerra, a morte do inimigo não é apenas um efeito colateral previsível, mas também, e acima de tudo, um componente inevitável e necessário à lógica dos conflitos. Evidente que isto contrasta com os dispositivos de proteção democrática, já que a morte é considerada um fracasso da ação repressiva do Estado, destinada, originariamente, à instauração de uma pacificação social. Talvez o preço dos excessos seja alto, mas, afinal, quem define esses limites quando a situação está no limite?

Neste sentido, Teixeira (2012) talvez tenha razão. O papel das forças da ordem, particularmente da polícia, passa a oscilar como um pêndulo entre a soberania e a gestão de ilegalismos. Assim, a polícia não mais apenas prende, ela também mata, e, junto com outros atores supralocais, tem papel importante na pacificação problemática do espaço urbano. A morte e as interações violentas ganham uma nova configuração nesse clima de conflitos. Nas se trata mais apenas do tradicional jogo do mocinho e do bandido; agora é uma guerra particular pelos lucros distribuídos no mercado ilegal. Um mercado rentável e de alto risco.

de antropologia política. São Paulo: Cosac Naify, 2003.

CARDOSO, Marcus. Quem tem direitos? Sobre o que dizem e pensam os moradores de duas favelas cariocas. Vivência, v. 1, n. 46, p. 159-168, 2015.

DAS, Veena; POOLE, Deborah. El estado y sus márgenes: etnografías comparadas. Cuadernos de Antropologia $y$ Sociologia, Buenos Aires, n. 27, p. 19-52, jul. 2008.

DIAS, Camila Caldeira Nunes. PCC: hegemonia nas prisões e monopólio da violência. São Paulo: Saraiva, 2013. DOWDNEY, Luke. De aviãozinho a soldado: o crescente envolvimento de crianças nas lutas de grupos armados do tráfico de drogas no Rio de Janeiro. In: OLIVEIRA, Nilson Vieira (Org.). Insegurança pública: reflexões sobre a criminalidade e a violência urbana. São Paulo: Nova Alexandria, 2002. p. 86-129.

ELIAS, Norbert; SCOTSON, John. Os estabelecidos e os outsiders: sociologia das relações de poder a partir de uma pequena comunidade. Rio de Janeiro: Jorge Zahar, 2000 .

FEFFERMANN, Marisa. Vidas arriscadas: o cotidiano dos jovens trabalhadores do tráfico. Petrópolis: Vozes, 2006.

FELTRAN, Gabriel de Santis. Fronteiras de tensão: um estudo sobre política e violência nas periferias de São Paulo. Campinas, 2008. Tese (Doutorado em Ciências Sociais) São Paulo, Universidade de Campinas, 2008.

FOUCAULT, Michel. História da sexualidade. Rio de 
Janeiro: Graal, 1985. v. 1 (A vontade de saber).

FOUCAULT, Michel. Em defesa da sociedade. São Paulo: Martins Fontes, 1999. Curso ministrado no Collège de France (1975-1976).

FOUCAULT, Michel. A vida dos homens infames. In: . Ditos e escritos. Rio de Janeiro: Forense Universitária, 2003. v. 4 (Estratégias, poder-saber). p. 203-222.

GARLAND, David. A cultura do controle: crime e ordem social na sociedade contemporânea. Rio de Janeiro: Revan, 2008.

HOBSBAWM, Eric. Bandidos. Rio de Janeiro: Paz e Terra, 2010.

LEITE, Márcia Pereira. Violência, risco e sociabilidade nas margens da cidade: percepções e formas de ação de moradores de favelas cariosas. In: SILVA, Luiz Antonio Machado da. (Org.). Vida sob cerco: violência e rotina nas favelas no Rio de Janeiro. Rio de Janeiro: Ed. Faperj, Nova Fronteira, 2008. p. 115-141.

LEMGRUBER, Julita. Controle da criminalidade: mitos e fatos. In: OLIVEIRA, Nilson Vieira (Org.). Insegurança pública: reflexões sobre a criminalidade e a violência urbana. São Paulo: Nova Alexandria, 2002. p. 155-185.

LIMA, João Marcelo Maciel de. Democracia e accountability: violência policial e prática de controle sobre a polícia militar do estado de São Paulo. Marília, 2011. Dissertação (Mestrado em Ciências Sociais) - Universidade de São Paulo, 2011.

MESQUITA NETO, Paulo. Violência policial no Brasil: abordagens teóricas e práticas de controle. In: PANDOLFI, Dulce; CARNEIRO, Leandro Piquet; CARVALHO, José Murilo (Org.). Cidadania, justiça e violência. Rio de Janeiro: Ed. Fundação Getúlio Vargas, 1999. p. 129-148.

MISSE, Michel. Crime e violência no Brasil contemporâneo: estudos de sociologia do crime e da violência urbana. Rio de Janeiro: Lumen Juris, 2006.

MISSE, Michel. Sobre a acumulação social da violência no Rio de Janeiro. Civitas: Revista de Ciências Sociais, v. 8, n. 3, p. 371-385, 2008.

MISSE, Michel. "Autos de resistência": uma análise dos homicídios cometidos por policiais na cidade do Rio de Janeiro (2001-2011). Rio de Janeiro: Ed. UFRJ, 2011.

PAIXÃO, Luis Antonio. Crime, controle social e consolidação da democracia: as metáforas da cidadania. In: REIS, Fábio Wanderley; O’DONNELL, Guillermo (Org.). A democracia no Brasil: dilemas e perspectivas. São
Paulo: Vértice, 1988. p. 168-199.

PINHEIRO, Paulo Sérgio. Transição política e não-estado de direito na República. In: SACHS, Ignacy; WILHELM, Jorge; PINHEIRO, Paulo Sérgio (Org.). Brasil: um século de transformações. São Paulo: Companhia das Letras, 2001. p. 260-305.

SANTOS, Wanderley Guilherme dos. Cidadania e justiça. Rio de Janeiro: Campus, 1979.

SILVA, Luiz Antonio Machado da (Org.). Vida sob cerco: violência e rotina nas favelas no Rio de Janeiro. Rio de Janeiro: Nova Fronteira: Ed. Faperj, 2008.

SILVA, Luiz Antonio Machado da. Sociabilidade violenta: por uma interpretação da criminalidade contemporânea no Brasil urbano. Sociedade e Estado, v. 19, n. 1, p. 53-84, 2004. SINHORETTO, Jacqueline. Controle social estatal e organização do crime em São Paulo. Dilemas: Revista de Estudos de Conflito e Controle Social, v. 7, n. 1, p. 167196, jan.-mar., 2014.

SOUZA, Luís Antônio Francisco de. Militarização da segurança pública no Brasil. In: MARTINS, Herbert Toledo; LOURENÇO, Luiz Claudio (Org.). Criminalidade, direitos humanos e segurança pública na Bahia. Salvador: Editora da UFRB, 2014. p. 15-36.

TEIXEIRA, Alessandra. Prisões da exceção: política penal e penitenciária no Brasil contemporâneo. Curitiba: Juruá, 2009.

TEIXEIRA, Alessandra. Construir a delinquência, articular a criminalidade: um estudo sobre a gestão dos ilegalismos na cidade de São Paulo. São Paulo, 2012. Tese (Doutorado) Universidade de São Paulo, 2012.

TELLES, Vera da Silva. A cidade nas fronteiras do legal e do ilegal. Belo Horizonte: Argumentum, 2011.

VELHO, Gilberto; ALVITO, Marcos (Org.). Cidadania e violência. Rio de Janeiro: Editora da FGV, 1996.

WHYTE, William Foote. Sociedade de esquina: a estrutura social de uma área urbana pobre e degradada. Rio de Janeiro: Jorge Zahar, 2005.

ZALUAR, Alba. Brasil na transição: cidadãos não vão ao paraíso. São Paulo em Perspectiva, v. 5, n. 1, p. 18-25, 1991.

ZALUAR, Alba. Condomínio do diabo. Rio de Janeiro: Revan: Editora da FGV, 1994.

ZALUAR, Alba. Crime, medo e política. In: ZALUAR, Alba; ALVITO, Marcos (Org.). Um século de favela. 2. ed. Rio de Janeiro: Editora da FGV, 1999. 


\title{
Risk, criminal market and violent interactions. A suburban gated community ethnography of a medium size city in São Paulo State hinterland
}

\begin{abstract}
The present article aims to show the dilemmas lived by the inhabitants from a suburban gated community of a medium size city in the São Paulo state hinterland. The discussion is based on the stand point of recent expansion of the criminal market and its connections with the increasingly life risk over the young inhabitants of the community as such. By the way of an ethnographic approach, the study focuses on the violent interaction between young people that work for the illegal drug market and the police. The main concern here is not only to address the conflicts, lethal violence and the strategies of survival of the residents related to the informal and illegal market, but also to address the conflict resolutions patterns within the so called crime tribunal.
\end{abstract}

Keywords: Risk, criminal market, violence, crime tribunal, police.

\section{Riesgo, mercado criminal e interacciones violentas. Una etnografía de un conjunto de viviendas en la periferia de una ciudad media del estado de}

\section{São Paulo}

\section{Resumen}

El presente artículo busca explorar los dilemas vividos por habitantes de un conjunto de viviendas periférico de una ciudad del interior del Estado de São Paulo. La discusión parte de la perspectiva de la expansión del mercado criminal en su conexión con la ampliación de los riesgos, sobre todo para los jóvenes habitantes del conjunto de viviendas. Por medio de una etnografía, el estudio trata de las interacciones violentas entre jóvenes ligados al mercado ilegal de drogas y a la policía. El artículo se dirige a identificar los conflictos, la violencia letal, y las estrategias de sobrevivencia de los habitantes del conjunto desde su inserción en el mercado informal e ilegal, y además a identificar los modelos de solución de conflictos en el interior del llamado tribunal del crimen.

Palabras clave: Riesgo, mercado del crimen, violencia, tribunal del crimen, policía.

Data de recebimento do artigo: 5/ 2016 Data de aprovação do artigo: 11/2016 